\title{
Clarifying and Revealing the Gender Differences in the Relationships of Lean and Fat Mass with Metabolic Syndrome Risk Factors in Asian Men and Women
}

\author{
Victor Hng Hang Goh \\ Curtin Medical School, Curtin University, Bentley, Australia
}

Email address:

victor.goh@curtin.edu.au

\section{To cite this article:}

Victor Hng Hang Goh. Clarifying and Revealing the Gender Differences in the Relationships of Lean and Fat Mass with Metabolic Syndrome Risk Factors in Asian Men and Women. World Journal of Public Health. Vol. 6, No. 1, 2021, pp. 17-24.

doi: $10.11648 /$ j.wjph.20210601.14

Received: February 23, 2021; Accepted: March 13, 2021; Published: March 30, 2021

\begin{abstract}
Objectives: To clarify the relationships of fat and lean mass with the metabolic syndrome risk factors in Asian men and women. Methods: This is a cross sectional study of 530 and 1326 Singaporean men and women. The lean mass index (LMI), fat mass index (FMI) and abdominal fat index (AbFI) were computed with height adjustments as with BMI, and were categorized into four groups to evaluated for their relationships with the various metabolic syndrome risk factors. Results: Men have 35\% more LMI, 57\% less FMI and 30\% less of AbFI than in women. Lean and fat mass have independent and gender-specific relationships with the various metabolic syndrome risk factors. Varying amounts of LMI in men have no bearing on the MetS risk factors. While in women, high LMI is associated with risk factors for metabolic health. High FMI in men is cardio-protective, while high FMI in women is associated with higher insulin resistance markers. High AbFI in both men and women is a predictor, possibly, of poorer metabolic health. BMI reflects the combined association of LMI, FMI and AbFI. Conclusions: The results clarify and reveal the clear gender differences in the relationships of LMI, FMI, AbFI and BMI with the various MetS risk factors. These news findings, together with known predicators of MetS such as age, physical exercise, male and female hormones, should form the basis to establish different and gender-specific management modalities for MetS.
\end{abstract}

Keywords: Fat Mass Index (FMI), Lean Mass Index (LMI), Abdominal Fat Mass Index (AbFI), Body Mass Index (BMI), Metabolic Syndrome (MetS), Metabolic Syndrome Risk Factors, Cardio-protection

\section{Introduction}

Metabolic syndrome (MetS) is linked to increased risk of multiple chronic diseases such as cardiovascular disease, diabetes, arthritis, chronic kidney disease, schizophrenia, and several types of cancer and of early death [1-3]. With the growing affluence, MetS is becoming a major health problem, not only in more advanced but also in developing countries [4]. In the US, the prevalence of MetS has reached an epidemic proportion of more than $30 \%$ among all adults [5]. With the increasing prevalence of MetS, there is a need to better understand the public health burden and to establish prevention strategies for its management. Metabolic syndrome is known to be associated with insulin resistance, dyslipidemia, hypertension, type- 2 diabetes and obesity [6]. The efforts to better understand MetS have been confounded by the lack of consistent associations with some of the clinical components of MetS, especially that of obesity. The association of obesity with MetS has been equivocal, and it may be abdominal obesity rather than general obesity that predicates the higher risks for MetS [7, 8]. A main reason for the ambiguity in the relationship between obesity and MetS is the inherent inaccuracy of the anthropometric indices used to define obesity. Body mass index (BMI), defined as total body mass divided by $\mathrm{m} 2$, has long been used as an index of obesity [9]. However, studies have shown that BMI is not an accurate index of obesity, principally because it neither differentiates between lean and fat mass. More correctly, BMI should be viewed as a body mass index including lean and fat mass that is 
adjusted for height $[10,11]$.

More recently, most of the anthropometric indices have been replaced by adiposity derived from dual X-ray energy absorptiometry (DXA), ultrasound and others scanners. However, even the DXA-derived percent body fat has its limitations. In general, women have about $10 \%$ more body fat than men, therefore expressing fat mass, as a percent does not reflect the actual amount of fat. A $20 \%$ body fat in a 200 pound-man is definitely more than a $20 \%$ body fat in a 100 -pound woman. As suggested earlier, the association with MetS may not be related to fat expressed in percent, but rather to the absolute amount of fat mass $[7,12]$.

It has long been assumed that only fat mass is associated with the increased risk of MetS. The question remains, does the amount of lean mass have any relationship with metabolic syndrome, if there is, what is it? The current study made use of the fat mass index (FMI), lean mass index (LMI) and abdominal fat index (AbFI) of a large cohort of Asian men and women and sought to clarify some of the abovementioned unresolved questions.

\section{Materials and Methods}

\subsection{Subjects}

The Institutional Review Board of the National University Hospital of Singapore approved this study. Each volunteer gave his/her written informed consent. Five hundred and thirty Singaporean men and 1320 Singaporean women, aged between $29 \mathrm{y}$ and $72 \mathrm{y}$, living in the community were recruited through advertisements in the media and through word of mouth. As the primary objective of the overall study was to evaluate the determinants of the natural aging process, only individuals without a history of major medical illnesses such as cancer, hypertension, thyroid dysfunction, diabetes, osteoporotic fracture, cardiovascular events, major sleep disorders, or major joint surgery were included in the study. Subjects were not paid for their participation. The cohorts of men and women represented the diverse spectrum of people in Singapore, ranging from those with low to high levels of education, working and non-working, and those in various types of vocation. Their profiles were typical of people in Singapore, which is a highly urbanized city-state with no rural population. The methodology used was previously reported [13].

\subsection{General Questionnaire}

Each subject answered a self-administered and investigator-guided questionnaire. Questions asked included their medical, social, sex, physical exercise, and family history.

\subsection{Biochemical and Hormone Measurements}

An overnight $12 \mathrm{~h}$ fasting blood sample was collected in the morning on any day between 9.00am and 11.00am for all men and postmenopausal women. For premenopausal women, the fasting blood sample was collected between Day 3-5 of their menstrual cycle. The sera were stored at $-80^{\circ} \mathrm{C}$ until analysis. Serum levels of total cholesterol (TC) and triglycerides (TG), high-density lipoprotein cholesterol (HDL), low-density lipoprotein cholesterol (LDL) and fasting glucose level (GLU) were measured by methods reported earlier [13]. Serum concentrations of insulin (INS) were measured in-house using the Axsym platform from Abbott Laboratories (Irving, TX).

\subsection{Whole Body DXA Scan}

Each volunteer had a whole body scan using the dualenergy X-ray absorptiometry (DXA) (Hologic, Bedford, MA, USA). The DXA machine calibrated the total fat and lean mass (TFM, TLM) and fat and lean mass in the various regional areas such as the limps, the abdomen and the trunk.

\subsection{Blood Pressures and Anthropometric Measures}

Trained clinical researchers, using a standardized manual sphygmomanometer, measured the brachial systolic (Sys) and diastolic (Dia) blood pressures, after subjects had rested for five minutes. Height in centimeter, and body weight in kilograms were measured for each volunteer.

\subsection{Intensity of Exercise (METmin)}

The intensity of exercise, expressed as metabolic equivalent of task-minutes (METmin) and its computation was reported earlier [14]. This score took into account the type, duration and frequency/week of exercise for each participant. The relevant data were gathered from the selfadministered and investigator-guided questionnaire.

\subsection{Definitions of Fat Mass Index (FMI) Lean Mass Index (LMI) and Abdominal Fat Index (AbFI)}

As with the BMI, height in meter-square $\left(\mathrm{m}^{2}\right)$ was used to adjust for differences in body size. Fat mass index (FMI) was calculated as total fat mass divided by $\mathrm{m}^{2}$ [15]. Likewise, lean mass index (LMI) and abdominal fat index (AbFI) were calculated with similar adjustment for height.

\subsection{Indices of Insulin Resistance}

Triglyceride/HDL ratio has been considered as a cardiovascular risk factor and has also been used as an index of insulin-resistant individuals. ${ }^{16}$ As suggested by McLaughlin et al [16], a TG/HDL of $>1.80$ was used as an indication that an individual is insulin resistant.

Homeostasis model assessment (HOMA) was also used as a measure of insulin resistance. The product of fasting insulin and glucose levels and dividing it by 22.5 gives the value for HOMA [17]. A HOMA value of $>2.8$ computed from a single fasting blood sample correlated well with other measures of insulin resistance. The data in the present study showed that TG/HDL and HOMA were positively and significantly correlated. 


\subsection{Body Mass Index (BMI)-, Fat Mass Index (FMI)-, Lean Mass Index (LMI)- and Abdominal Fat Index (AbFI)-groups}

Based on the normal distribution for the Singaporean men and women, four groups each for the FMI, LMI, AbFI and BMI were categorized: Group\#1: Low $(<5 \%)$, Group\#2: Normal ( $>5 \%$ to $85 \%$ ), Group\#3: High ( $>85 \%$ to $95 \%$ ) and Group\#4: Excess ( $>95$ percentile). These different groups were used solely to evaluate their associations with the various MetS risk factors.

\subsection{Statistical Analysis}

Statistical analyses were performed using SPSS for windows version 27.0 (Armond, NY). Basic descriptive statistics and multivariate analyses coupled with the Bonferroni correction for multiple comparisons were used on continuous measurements. Age and the intensity of exercise (METmin) were shown in our earlier studies to correlate with different body composition, and with various metabolic factors [18]. The estimated marginal means with the
Bonferroni correction for multiple comparisons allows for the independent associations of LMI, FMI, AbFI and BMI with the various MetS risk factors. The four levels allow for evaluating the relationships, not only of the high and excess but also the low amount of body composition with the various MetS risk factors.

\section{Results}

Table 1 shows the $5^{\text {th }}, 50^{\text {th }}, 85^{\text {th }}$ and $95^{\text {th }}$ percentiles to categorise the four groups of LMI, FMI, AbFI and BMI. These body composition profiles reveal the quantitative differences of these indices between Singaporean men and women. Using the values at the $50^{\text {th }}$ percentile, the BMI and LMI in men, respectively, are $7.8 \%$ and $35.9 \%$ higher than corresponding values in women (Table 1). On the other hand, men have $57.2 \%$ less fat mass than women (Table 1 ). What is interesting is when the amount of abdominal fat was heightadjusted, Singaporean men have $33.8 \%$ less of abdominal fat than in women, which is contrary to the prevailing assertion that men have more abdominal fat than women [19].

Table 1. Percentile values of various body indices in men and women.

\begin{tabular}{|c|c|c|c|c|}
\hline $\operatorname{Men}(n=530)$ & $5.0 \%$ & $50 \%$ & $85 \%$ & $95 \%$ \\
\hline BMI $\left(\mathrm{kg} / \mathrm{m}^{2}\right)$ & 19.7 & $23.5(7.8 \%)$ & 26.8 & 28.5 \\
\hline LMI $\left(\mathrm{kg} / \mathrm{m}^{2}\right)$ & 14.7 & $17.4(35.9 \%)$ & 19.3 & 20.6 \\
\hline FMI $\left(\mathrm{kg} / \mathrm{m}^{2}\right)$ & 2.89 & $5.16(-57.2 \%)$ & 7.00 & 7.94 \\
\hline $\operatorname{AbFI}\left(\mathrm{kg} / \mathrm{m}^{2}\right)$ & 0.66 & $1.42(-33.8 \%)$ & 2.02 & 2.30 \\
\hline Women $(n=1326)$ & $5 \%$ & $50 \%$ & $85 \%$ & $95 \%$ \\
\hline LMI $\left(\mathrm{kg} / \mathrm{m}^{2}\right)$ & 10.7 & 12.8 & 14.5 & 15.9 \\
\hline FMI $\left(\mathrm{kg} / \mathrm{m}^{2}\right)$ & 5.33 & 8.11 & 10.3 & 11.9 \\
\hline $\mathrm{AbFI}\left(\mathrm{kg} / \mathrm{m}^{2}\right)$ & 1.04 & 1.90 & 2.50 & 2.99 \\
\hline
\end{tabular}

* Percent in brackets denote the differences between the values at the $50^{\text {th }}$ percentile in men and corresponding values in women.

The most significant finding of the present study is that LMI, FMI and AbFI are independently and differentially associated with the various MetS risk factors, and in several instances, with very clear gender differences (Tables $2-4$ ).

This, perhaps is the first report showing that lean mass, independent of FMI and AbFI, is associated with some MetS risk factors in women but not in men (Table 2). Varying levels of LMI in men are not associated with any significant differences in any of the MetS risk factors (Table 2). In women, on the other hand, high levels of LMI are associated with poorer MetS risk factors when compared to those in women with normal levels of LMI (LMI\#2). The increasing levels of LMI are associated with a progressive decrease in HDL and increases in TC/HDL, glucose, insulin and HOMA levels (Table 2). In addition, the levels of TG and TG/HDL, though not statistically different, tend to be higher in women with higher LMI when compared with those with normal levels of LMI (Table 2).

Another clear gender difference is the association of FMI with the MetS risk factors. In men, after adjusting for AbFI and LMI, higher FMI appears to be cardio-protective. At excess levels (FMI\#4), diastolic blood pressure, TC, TG, TG/HDL, and the atherogenic index (TC/HDL) are significantly lower than in men with normal FMI (FMI\#2) (Table 3). However, glucose, insulin and HOMA levels are not significantly different when compared those with normal levels of FMI (Table 3). These observations are noted in men who have more then $50 \%$ less FMI than in women.

In women, on the other hand, high FMI (FMI\#4) appears to be adverse to metabolic health, especially for the glucose metabolism. Women with excess FMI have significantly higher INS and HOMA levels when compared to those in women with lower FMI levels (FMI\#2 \& FMI\#3) (Table 3). As in men, excess FMI (FMI\#4) appears to the cardioprotective; though not statistically significant, levels of TG, and TG/HDL are trending lower and HDL levels trending higher when compared to corresponding levels in women with normal FMI (FMI\#2) (Table 3). 
Table 2. Comparisons of various metabolic risk factors among the 4 LMI groups in both men and women with Age, METmin, FMI, and AbFI as covariates.

\begin{tabular}{|c|c|c|c|c|c|}
\hline Men & $\begin{array}{l}\text { LMI\#1 } \\
(n=24)\end{array}$ & $\begin{array}{l}\text { LMI\#2 } \\
(n=374)\end{array}$ & $\begin{array}{l}\text { LMI\#3 } \\
(n=45)\end{array}$ & $\begin{array}{l}\text { LMI\#4 } \\
(n=24)\end{array}$ & $P$ values \\
\hline $\mathrm{LMI}\left(\mathrm{kg} / \mathrm{m}^{2}\right)$ & $13.9+0.22$ & $17.2+1.10$ & $20.0+0.41$ & $21.8+0.34$ & $1 \mathrm{v} 2,3,4(<0.001,<0.001,<0.001), 2 \mathrm{v} 3,4(<0.001,<0.001), 3 \mathrm{v} 4(<0.001)$ \\
\hline Sys B/P (mm Hg) & $121+2.93$ & $128+0.74$ & $129+2.16$ & $131+2.99$ & NS \\
\hline $\mathrm{Dia} \mathrm{B} / \mathrm{P}(\mathrm{mm} \mathrm{Hg})$ & $76+1.90$ & $80+0.48$ & $81+1.40$ & $81+1.93$ & NS \\
\hline $\mathrm{TC}(\mathrm{mg} / \mathrm{dl})$ & $5.88+0.21$ & $5.74+0.05$ & $5.80+0.15$ & $5.60+0.21$ & NS \\
\hline $\mathrm{TG}(\mathrm{mmol} / \mathrm{l})$ & $1.24+0.14$ & $1.48+0.03$ & $1.59+0.10$ & $1.39+0.14$ & NS \\
\hline $\mathrm{TG} / \mathrm{HDL}$ & $0.94+0.14$ & $1.21+0.04$ & $1.33+0.11$ & $1.08+0.15$ & NS \\
\hline HDL (mg/dl) & $1.41+0.06$ & $1.34+0.02$ & $1.36+0.04$ & $1.39+0.06$ & NS \\
\hline LDL (mg/dl) & $3.92+0.19$ & $3.74+0.05$ & $3.74+0.14$ & $3.62+0.19$ & NS \\
\hline TC/HDL & $4.29+0.21$ & $4.48+0.05$ & $4.47+0.16$ & $4.17+0.22$ & NS \\
\hline GLU (mmol/l) & $4.73+0.14$ & $4.94+0.04$ & $4.91+0.11$ & $5.03+0.15$ & NS \\
\hline INS (mIU/L) & $6.00+0.72$ & $7.31+0.18$ & $8.26+0.53$ & $8.26+0.74$ & NS \\
\hline HOMA & $1.28+0.19$ & $1.65+0.05$ & $1.85+0.14$ & $1.89+0.19$ & NS \\
\hline Women & $\begin{array}{l}\text { LMI\#1 } \\
(n=67)\end{array}$ & $\begin{array}{l}\text { LMI\#2 } \\
(n=1063)\end{array}$ & $\begin{array}{l}\text { LMI\#3 } \\
(n=130)\end{array}$ & $\begin{array}{l}\text { LMI\#4 } \\
(n=66)\end{array}$ & $P$ values \\
\hline LMI $\left(\mathrm{kg} / \mathrm{m}^{2}\right)$ & $10.3+0.06$ & $12.7+0.03$ & $15.1+0.03$ & $16.6+0.10$ & $1 \mathrm{v} 3,4(<0.001,<0.001), 2 \mathrm{v} 3,4(<0.001,<0.001), 3 \mathrm{v} 4(<0.001)$ \\
\hline Sys B/P (mm Hg) & $123+2.00$ & $121+0.54$ & $123+1.01$ & $123+2.07$ & NS \\
\hline $\mathrm{Dia} \mathrm{B} / \mathrm{P}(\mathrm{mm} \mathrm{Hg})$ & $78+1.19$ & $77+0.32$ & $78+0.61$ & $77+1.24$ & NS \\
\hline $\mathrm{TC}(\mathrm{mg} / \mathrm{dl})$ & $5.66+0.11$ & $5.65+0.03$ & $5.68+0.06$ & $5.60+0.11$ & NS \\
\hline $\mathrm{TG}(\mathrm{mmol} / \mathrm{l})$ & $1.00+0.29$ & $1.16+0.08$ & $1.27+0.15$ & $1.38+0.30$ & NS \\
\hline TG/HDL & $0.60+0.22$ & $0.76+0.06$ & $0.92+0.11$ & $1.14+0.23$ & NS \\
\hline HDL (mg/dl) & $1.80+0.04$ & $1.68+0.01$ & $1.36+0.04$ & $1.39+0.06$ & $1 \mathrm{v} 2,3,4(0.045,<0.001,<0.001), 2 \mathrm{v} 3,4(0.006,<0.001), 3 \mathrm{v} 4(0.023)$ \\
\hline $\operatorname{LDL}(\mathrm{mg} / \mathrm{dl})$ & $3.42+0.10$ & $3.49+0.03$ & $3.53+0.05$ & $3.56+0.10$ & NS \\
\hline TC/HDL & $3.26+0.11$ & $3.50+0.03$ & $3.75+0.06$ & $4.19+0.22$ & $1 \mathrm{v} 3,4(0.001,<0.001), 2 \mathrm{v} 3,4(<0.001,<0.001), 3 \vee 4(0.002)$ \\
\hline GLU (mmol/l) & $4.73+0.06$ & $4.73+0.02$ & $4.81+0.03$ & $4.99+0.07$ & $1,2 \mathrm{v} 4(0.038,0.001)$ \\
\hline INS (mIU/L) & $5.39+0.41$ & $6.21+0.11$ & $7.41+0.21$ & $9.73+0.43$ & $1 \mathrm{v} 3,4(<0.001,<0.001), 2 \mathrm{v} 3,4(<0.001,<0.001), 3 \mathrm{v} 4(<0.001)$ \\
\hline HOMA & $1.14+0.11$ & $1.33+0.03$ & $1.61+0.05$ & $2.31+0.11$ & $1 \mathrm{v} 3,4(0.001,<0.001), 2 \mathrm{v} 3,4(<0.001,<0.001), 3 \mathrm{v} 4(<0.001)$ \\
\hline
\end{tabular}

* Values are reported as mean $+\mathrm{SE}$

Table 3. Comparisons of various metabolic risk factors among the 4 FMI groups in both men and women with Age, METmin, LMI, and AbFI as covariates.

\begin{tabular}{|c|c|c|c|c|c|}
\hline Men & FMI\#1 $(n=24)$ & FMI\#2 $(n=372)$ & FMI\#3 $(n=47)$ & FMI\#4 $(n=24)$ & $P$ values \\
\hline FMI $\left(\mathrm{kg} / \mathrm{m}^{2}\right)$ & $2.36+0.08$ & $5.00+0.05$ & $7.44+0.04$ & $8.81+0.37$ & $\begin{array}{l}1 \mathrm{v} 2,3,4(<0.001,<0.001,<0.001) \\
2 \mathrm{v} 3,4(<0.001,<0.001), 3 \mathrm{v} 4(<0.001)\end{array}$ \\
\hline Sys B/P (mm Hg) & $133+3.52$ & $128+0.76$ & $126+2.48$ & $124+3.47$ & NS \\
\hline Dia B/P (mm Hg) & $82+2.25$ & $80+0.49$ & $78+1.59$ & $73+2.22$ & $2 \mathrm{v} 4(0.010)$ \\
\hline $\mathrm{TC}(\mathrm{mg} / \mathrm{dl})$ & $5.57+0.24$ & $5.84+0.05$ & $5.36+0.17$ & $5.13+0.21$ & $2 \mathrm{v} 4(0.029)$ \\
\hline $\mathrm{TG}(\mathrm{mmol} / \mathrm{l})$ & $1.52+0.16$ & $1.55+0.04$ & $1.08+0.12$ & $1.07+0.16$ & $2 \mathrm{v} 3,4(0.001,0.030)$ \\
\hline TG/HDL & $1.22+0.17$ & $1.28+0.04$ & $0.80+0.12$ & $0.80+0.17$ & $2 \mathrm{v} 3,4(0.002,0.043)$ \\
\hline $\mathrm{LDL}(\mathrm{mg} / \mathrm{dl})$ & $3.54+0.22$ & $3.82+0.05$ & $3.49+0.16$ & $3.24+0.22$ & NS \\
\hline TC/HDL & $4.21+0.25$ & $4.58+0.05$ & $3.93+0.18$ & $3.75+0.25$ & $2 \mathrm{v} 3,4(0.004,0.009)$ \\
\hline GLU (mmol/l) & $4.97+0.17$ & $4.91+0.04$ & $4.95+0.12$ & $5.22+0.17$ & NS \\
\hline INS (mIU/L) & $8.09+0.86$ & $7.31+0.19$ & $8.10+0.61$ & $7.57+0.85$ & NS \\
\hline HOMA & $1.85+0.22$ & $1.62+0.05$ & $1.86+0.16$ & $1.80+0.22$ & NS \\
\hline Women & FMI\#1 $(n=69)$ & FMI\#2 $(n=1058)$ & FMI\#3 $(n=133)$ & FMI\#4 $(n=66)$ & $P$ values \\
\hline Sys B/P (mm Hg) & $121+2.31$ & $121+0.57$ & $122+1.23$ & $122+2.47$ & NS \\
\hline Dia B/P (mm Hg) & $76+1.38$ & $77+0.34$ & $77+0.73$ & $77+1.48$ & NS \\
\hline $\mathrm{TC}(\mathrm{mg} / \mathrm{dl})$ & $5.62+0.13$ & $5.67+0.03$ & $5.61+0.07$ & $5.59+0.14$ & NS \\
\hline $\mathrm{TG}(\mathrm{mmol} / \mathrm{l})$ & $1.33+0.34$ & $1.27+0.08$ & $0.94+0.18$ & $1.39+0.14$ & NS \\
\hline TG/HDL & $0.86+0.25$ & $0.87+0.06$ & $0.62+0.13$ & $0.51+0.27$ & NS \\
\hline HDL (mg/dl) & $1.69+0.05$ & $1.64+0.01$ & $1.70+0.03$ & $1.77+0.05$ & NS \\
\hline LDL (mg/dl) & $3.38+0.11$ & $3.53+0.03$ & $3.46+0.06$ & $3.40+0.12$ & NS \\
\hline $\mathrm{TC} / \mathrm{HDL}$ & $3.44+0.13$ & $3.62+0.03$ & $3.49+0.07$ & $3.35+0.13$ & NS \\
\hline GLU (mmol/l) & $4.77+0.07$ & $4.75+0.02$ & $4.72+0.04$ & $4.90+0.08$ & NS \\
\hline INS (mIU/L) & $7.15+0.47$ & $6.58+0.12$ & $6.04+0.25$ & $8.33+0.50$ & $2,3 \mathrm{v} 4(0.007,<0.001)$ \\
\hline HOMA & $1.58+0.12$ & $1.42+0.03$ & $1.27+0.06$ & $1.95+0.13$ & $2,3 \mathrm{v} 4(0.001,<0.001)$ \\
\hline
\end{tabular}

\footnotetext{
* Values are reported as mean+SE
} 
Table 4. Comparisons of various metabolic risk factors among the 4 AbFI groups in both men and women with Age, METmin, FMI, and LMI as covariates.

\begin{tabular}{|c|c|c|c|c|c|}
\hline Men & AbFI\#1 (n=25) & AbFI\#2 (n=372) & AbFI\#3 (n=47) & AbFI\#4 (n=23) & P values \\
\hline $\operatorname{AbFI}\left(\mathrm{kg} / \mathrm{m}^{2}\right)$ & $0.46+0.03$ & $1.36+0.02$ & $2.16+0.01$ & $2.57+0.04$ & $\begin{array}{l}1 \mathrm{v} 2,3,4(<0.001,<0.001,<0.001), 2 \mathrm{v} 3,4 \\
(<0.001,<0.001), 3 \mathrm{v} 4(<0.001)\end{array}$ \\
\hline Sys B/P (mm Hg) & $126+3.40$ & $127+0.76$ & $131+2.50$ & $132+3.60$ & NS \\
\hline $\mathrm{TC}(\mathrm{mg} / \mathrm{dl})$ & $5.24+0.24$ & $5.78+0.05$ & $5.66+0.18$ & $5.93+0.25$ & NS \\
\hline $\mathrm{TG}(\mathrm{mmol} / \mathrm{l})$ & $1.05+0.16$ & $1.46+0.04$ & $1.75+0.12$ & $1.54+0.17$ & $1 v 3(0.014)$ \\
\hline TG/HDL & $0.70+0.17$ & $1.21+0.04$ & $1.48+0.13$ & $1.19+0.18$ & $1 \mathrm{v} 2,3(0.018,0.007)$ \\
\hline HDL (mg/dl) & $1.61+0.07$ & $1.34+0.02$ & $1.22+0.05$ & $1.34+0.07$ & $1 \mathrm{v} 2,3(0.001,<0.001)$ \\
\hline $\mathrm{LDL}(\mathrm{mg} / \mathrm{dl})$ & $3.24+0.22$ & $3.78+0.05$ & $3.67+0.16$ & $3.91+0.19$ & NS \\
\hline $\mathrm{TC} / \mathrm{HDL}$ & $3.39+0.25$ & $4.48+0.06$ & $4.76+0.18$ & $4.57+0.22$ & $1 \mathrm{v} 2,3,4(<0.001,0.001,0.024)$ \\
\hline GLU (mmol/l) & $4.82+0.16$ & $4.90+0.04$ & $4.97+0.12$ & $5.58+0.15$ & $1 \mathrm{v} 2,3,4(0.030,0.030,0.001)$ \\
\hline INS (mIU/L) & $6.41+0.86$ & $7.17+0.19$ & $8.84+0.63$ & $10.18+0.90$ & $1,2 \mathrm{v} 4(0.047,0.009)$ \\
\hline HOMA & $1.38+0.22$ & $1.57+0.05$ & $2.01+0.16$ & $2.67+0.19$ & $1,2,3 \mathrm{v} 4(0.002,<0.001,0.032)$ \\
\hline Women & AbFI\#1 (n=66) & AbFI\#2 (n=1061) & AbFI\#3 (n=134) & AbFI\#4 (n=65) & $P$ values \\
\hline Sys B/P (mm Hg) & $121+2.33$ & $121+0.58$ & $122+1.23$ & $125+2.52$ & NS \\
\hline $\mathrm{Dia} \mathrm{B} / \mathrm{P}(\mathrm{mm} \mathrm{Hg})$ & $75+1.40$ & $77+0.35$ & $78+0.74$ & $79+1.51$ & NS \\
\hline $\mathrm{TC}(\mathrm{mg} / \mathrm{dl})$ & $5.68+0.13$ & $5.64+0.03$ & $5.70+0.07$ & $5.65+0.14$ & NS \\
\hline $\mathrm{TG}(\mathrm{mmol} / \mathrm{l})$ & $1.03+0.34$ & $1.20+0.08$ & $1.15+0.18$ & $1.16+0.37$ & NS \\
\hline TG/HDL & $0.63+0.26$ & $0.82+0.06$ & $0.78+0.14$ & $0.78+0.28$ & NS \\
\hline HDL (mg/dl) & $1.89+0.05$ & $1.66+0.01$ & $1.61+0.03$ & $1.65+0.06$ & $1 \mathrm{v} 2,3,4(<0.001,<0.001,0.027)$ \\
\hline $\mathrm{LDL}(\mathrm{mg} / \mathrm{dl})$ & $3.39+0.12$ & $3.50+0.03$ & $3.55+0.06$ & $3.41+0.12$ & NS \\
\hline $\mathrm{TC} / \mathrm{HDL}$ & $3.13+0.13$ & $3.55+0.03$ & $3.73+0.07$ & $3.65+0.14$ & $1 \mathrm{v} 2,3(0.006,0.001)$ \\
\hline GLU (mmol/l) & $4.80+0.07$ & $4.74+0.02$ & $4.76+0.04$ & $4.99+0.08$ & $2,3 v 4(0.021,0.017)$ \\
\hline INS (mIU/L) & $6.47+0.48$ & $6.38+0.12$ & $6.79+0.26$ & $8.78+0.52$ & $1,2,3 \mathrm{v} 4(0.026,<0.001,<0.001)$ \\
\hline HOMA & $1.41+0.12$ & $1.37+0.03$ & $1.45+0.07$ & $2.08+0.13$ & $1,2,3 \mathrm{v} 4(<0.001,<0.001,<0.001)$ \\
\hline
\end{tabular}

* Values are reported as mean $+\mathrm{SE}$

Table 5. Comparisons of various metabolic risk factors among the 4 BMI groups in both men and women with Age and METmin as covariates.

\begin{tabular}{|c|c|c|c|c|c|c|c|}
\hline Men & BMI\#1 $(n=21)$ & $\begin{array}{l}\text { BMI\#2 } \\
(n=375)\end{array}$ & \multicolumn{2}{|c|}{ BMI\#3 $(n=41)$} & \multicolumn{2}{|c|}{$\begin{array}{l}\text { BMII\#4 } \\
(\mathrm{n}=24)\end{array}$} & $P$ values \\
\hline BMI $\left(\mathrm{kg} / \mathrm{m}^{2}\right)$ & $19.1+0.12$ & $23.3+0.09$ & \multicolumn{2}{|c|}{$27.6+0.07$} & \multicolumn{2}{|c|}{$30.9+0.59$} & $\begin{array}{l}1 \mathrm{v} 2,3,4(<0.001,<0.001,<0.001), 2 \mathrm{v} 3,4(<0.001,<0.001), 3 \mathrm{v} 4 \\
(<0.001)\end{array}$ \\
\hline Sys B/P (mm Hg) & $125+2.80$ & $127+0.75$ & \multicolumn{2}{|l|}{$130+2.27$} & \multicolumn{2}{|c|}{$133+3.00$} & NS \\
\hline $\mathrm{Dia} \mathrm{B} / \mathrm{P}(\mathrm{mm} \mathrm{Hg})$ & $78+1.81$ & $79+0.48$ & \multicolumn{2}{|l|}{$82+1.50$} & \multicolumn{2}{|c|}{$82+1.90$} & NS \\
\hline $\mathrm{TC}(\mathrm{mg} / \mathrm{dl})$ & $5.68+0.19$ & $5.74+0.05$ & \multicolumn{2}{|c|}{$5.84+0.16$} & \multicolumn{2}{|c|}{$5.70+0.21$} & NS \\
\hline $\mathrm{TG}(\mathrm{mmol} / \mathrm{l})$ & $1.17+0.13$ & $1.47+0.04$ & \multicolumn{2}{|c|}{$1.70+0.11$} & \multicolumn{2}{|c|}{$1.49+0.14$} & $1 \mathrm{v} 3(0.013)$ \\
\hline HDL (mg/dl) & $1.57+0.06$ & $1.34+0.02$ & \multicolumn{2}{|c|}{$1.29+0.05$} & \multicolumn{2}{|c|}{$1.25+0.06$} & $1 \mathrm{v} 2,3,4(0.001,0.001,0.001)$ \\
\hline LDL (mg/dl) & $3.60+0.18$ & $3.75+0.05$ & \multicolumn{2}{|c|}{$3.78+0.14$} & \multicolumn{2}{|c|}{$3.78+0.19$} & NS \\
\hline $\mathrm{TC} / \mathrm{HDL}$ & $3.73+0.21$ & $4.47+0.06$ & \multicolumn{2}{|c|}{$4.66+0.17$} & \multicolumn{2}{|c|}{$4.68+0.22$} & $1 \mathrm{v} 2,3,4(0.004,0.003,0.012)$ \\
\hline GLU (mmol/l) & $4.82+0.14$ & $4.91+0.04$ & \multicolumn{2}{|c|}{$5.03+0.11$} & \multicolumn{2}{|c|}{$5.18+0.14$} & NS \\
\hline INS (mIU/L) & $4.75+0.77$ & $7.00+0.21$ & \multicolumn{2}{|c|}{$11.34+0.62$} & \multicolumn{2}{|c|}{$10.69+0.81$} & $1 \mathrm{v} 2,3,4(0.029,<0.001,<0.001), 2 \mathrm{v} 3,4(<0.001,<0.001)$ \\
\hline HOMA & $1.01+0.19$ & $1.55+0.05$ & \multicolumn{2}{|c|}{$2.64+0.16$} & \multicolumn{2}{|c|}{$2.48+0.21$} & $1 \mathrm{v} 2,3,4(0.044,<0.001,<0.001), 2 \mathrm{v} 3,4(<0.001,<0.001)$ \\
\hline $\operatorname{BMI}\left(\mathrm{kg} / \mathrm{m}^{2}\right)$ & $17.2+0.09$ & $21.6+0.06$ & $26.5+0.08$ & $29.8+$ & -0.18 & $1 \mathrm{v} 2$ & $(<0.001,<0.001,<0.001), 2 \mathrm{v} 3,4(<0.001,<0.001), 3 \mathrm{v} 4(<0.001)$ \\
\hline Sys B/P (mm Hg) & $117+1.04$ & $122+0.54$ & $124+1.50$ & $129+$ & 2.17 & $1 \mathrm{v} 2$ & $(0.001,0.001,<0.001), 2 \mathrm{v} 4(0.004)$ \\
\hline $\mathrm{Dia} \mathrm{B} / \mathrm{P}(\mathrm{mm} \mathrm{Hg})$ & $75+0.63$ & $77+0.32$ & $80+0.90$ & $80+1$ & .30 & $1 \mathrm{v} 2$ & $(0.002,<0.001,<0.001), 2 \mathrm{v} 3(0.009)$ \\
\hline $\mathrm{TC}(\mathrm{mg} / \mathrm{dl})$ & $5.51+0.06$ & $5.68+0.03$ & $5.73+0.08$ & $5.68+$ & -0.12 & $1 \mathrm{v} 2$ & 35) \\
\hline $\mathrm{TG}(\mathrm{mmol} / \mathrm{l})$ & $0.91+0.15$ & $1.22+0.08$ & $1.37+0.22$ & $1.44+$ & -0.31 & NS & \\
\hline TG/HDL & $0.53+0.12$ & $0.82+0.06$ & $1.04+0.17$ & $1.15+$ & -0.24 & NS & \\
\hline HDL (mg/dl) & $1.83+0.02$ & $1.66+0.01$ & $1.44+0.03$ & $1.40+$ & -0.05 & $1 \mathrm{v} 2$ & $(<0.001,<0.001,<0.001), 2 \vee 3,4(<0.001,<0.001)$ \\
\hline LDL (mg/dl) & $3.27+0.05$ & $3.53+0.03$ & $3.68+0.07$ & $3.64+$ & -0.11 & $1 \mathrm{v} 2$ & $(<0.001,<0.001,0.011)$ \\
\hline TC/HDL & $3.11+0.06$ & $3.57+0.03$ & $4.18+0.08$ & $4.28+$ & -0.12 & $1 \mathrm{v} 2$ & $(<0.001,<0.001,<0.001), 2 \mathrm{v} 3,4(<0.001,<0.001)$ \\
\hline GLU (mmol/l) & $4.64+0.03$ & $4.74+0.02$ & $4.91+0.05$ & $5.20+$ & -0.07 & $1 \mathrm{v} 2$ & $(0.032,<0.001,<0.001) 2 \mathrm{v} 3,4(0.003,<0.001), 3 \mathrm{v} 4(0.003)$ \\
\hline INS (mIU/L) & $4.51+0.22$ & $6.34+0.11$ & $10.07+0.32$ & 12.40 & +0.46 & $1 \mathrm{v} 2$ & $(<0.001,<0.001,<0.001), 2 \mathrm{v} 3,4(<0.001,<0.001), 3 \mathrm{v} 4(<0.001)$ \\
\hline HOMA & $0.94+0.06$ & $1.36+0.03$ & $2.22+0.08$ & $3.02+$ & -0.12 & $1 \mathrm{v} 2$ & $(<0.001,<0.001,<0.001), 2 \mathrm{v} 3,4(<0.001,<0.001), 3 \mathrm{v} 4(<0.001)$ \\
\hline
\end{tabular}

\footnotetext{
* Values are reported as mean+SE
} 
After adjusting for the effects of FMI and LMI, AbFI is associated variably with the different MetS risk factors in both men and women. High levels of AbFI (AbFI\#4) in both men and women are associated with significantly higher levels of GLU, INS and HOMA when compared with those with normal levels of AbFI (AbFI\#2) (Table 4). On the other hand, in both gender, very lower levels of AbFI (AbFI\#1), are associated with significantly lower levels of GLU, INS, HOMA, TC/HDL as well as higher levels of HDL when compared to those with normal AbFI (AbFI\#2) (Table 4). In men only, low AbFI (AbFI\#1) is associated with significantly lower TG and TG/HDL levels when compared to those with normal levels of AbFI (Table 4).

The BMI represents the total body mass including those of LMI, FMI, AbFI and bone mass. Therefore, after adjusting only for age and METmin, the associations of BMI with the various MetS risk factors represent the combined effects those of LMI, FMI and AbFI. In men, high BMI (BMI\#4) is associated with significantly higher INS and HOMA levels when compared to men with normal BMI (BMI\#2), which appears to be similar to those of high AbFI alone (Table 4 \& 5). Similarly, as with low AbFI (AbFI\#1), low BMI (BMI\#1) is significantly associated with lower TG, TG/HDL, TC/HDL, INS and HOMA as well as higher HDL levels than in men with normal BMI (BMI\#2) (Table 5). These observations are not unexpected as it was shown that high LMI levels in men are not associated with any significant differences in the various MetS risk factors as compared to those with (Table 2 $\& 3$ ). While high FMI in men are cardio-protective (Table 3).

Unlike in men, high BMI (BMI\#3 \& BMI\#4) in women are associated with more adverse levels of the MetS risk factors (Table 5). As shown earlier, high levels of LMI, FMI and $\mathrm{AbFI}$ in women are independently associated with more adverse levels of the MetS risk factors (Tables 2-4). The combined effects of these three indices, as in the high BMI group, further intensify the increases in INS, GLU and HOMA than by the independent associations of LMI, FMI and AbFI (Tables 2-5). In addition, the combined effects have led to significantly higher systolic and diastolic blood pressures, TC/HDL and significantly lower levels of HDL when compared to women with normal BMI (BMI\#2) (Table 5). As with men, low BMI (BMI\#1) was associated with significantly lower levels of systolic and diastolic blood pressure, TC, LDL, TC/HDL, GLU, INS and HOMA and higher levels of HDL, and at the same time, although not statistically significant, lower levels of TG and TG/HDL when compared to those with normal BMI levels (Table 5).

\section{Discussion}

The degree of adiposity appears to be one of the key risk factors of the metabolic syndrome $[5,20]$, but its precise relationship with MetS has been equivocal [10, 21, 22]. The present study made use of the height-adjusted indices, which provide more accurate and equitable determinations of both lean and fat mass in men and women. Their use has provided clarity in the relationships of the LMI, FMI, AbFI and BMI with the various MetS risk factors, and revealed the gender differences in these relationships.

This is the first study that shows the gender-based relationships between LMI and the various MetS risk factors. While in men, LMI appears to have no bearing on any of the MetS risk factors, in women high LMI is associated with worsening of risk factors related to both cardiovascular health and insulin resistance. These observations occur in spite of women having more than $35 \%$ less of LMI than in men, imply that lean mass in woman is not only quantitatively but may also be qualitatively different from those in men. If a qualitative difference exists, what might it be? Most adipose tissues are stored subcutaneously, especially in the gluteal-femoral region. However, there are adipose tissues in ectopic regions outside the subcutaneous sites including the muscles, liver, and the abdomen [23]. Intermascular adipose tissue (IMAT) is found beneath the fascia and within the muscle. It might be possible that lean mass in women may be infiltrated with more IMAT than those in men. Previous research has indicated that excess IMAT can lead to increase in insulin resistance [24, 25]. Therefore, if lean mass in women have excess amount of IMAT, it may then explain that the high lean mass in women is associated with higher levels of the insulin resistance markers.

Another interesting an important gender difference is how FMI relates to the various MetS risk factors. In men, high FMI appears to be cardio-protective and is not a predicator of the other aspects of the MetS. In women, on the other hand, high FMI is associated with higher levels of the insulin resistance markers, while not showing any difference in risk factors for cardiovascular health. The cardio-protection of FMI in men cannot be accounted for merely by the quantum of FMI, as similar or higher levels of FMI in women, did not show any degree of the cardio-protection seen in men. Therefore, it would appear that cardio-protection of FMI is gender specific and not dose dependent. On the other hand, adverse relationship of FMI with insulin resistance occurs in women with excess FMI and may thus be a dose-dependent phenomenon. This suggestion is supported by the observation that in women with high levels of FMI, much higher than those present in men, are not associated with higher levels of the insulin resistance markers until the level reaches the excess level. The gender difference in FMI relationship with the MetS risk factors contrast with the earlier suggestion that subcutaneous adipose tissue (SAT) is a negative predicator of MetS and is cardio-protective [26, 27].

The present study also confirms that it is the high accumulation of abdominal fat and not general subcutaneous fat (SAT) that is adverse to metabolic health, as suggested earlier [28]. In both men and women, high AbFI is associated higher levels of glucose, insulin and HOMA implying that its effect is directed at the carbohydrate metabolism. It is also clear that the lower the abdominal fat is, the better it is for metabolic health. The limitation of the AbFI is the lack of 
clarity on the differential amount of abdominal subcutaneous from the visceral adipose tissue (VAT). The VAT has been shown to be more adverse to the metabolic health than the subcutaneous fat [29]. Therefore, modality to reduce adiposity in both men and women must be directed towards reducing abdominal fat so as to mitigate its risk on MetS, especially that for type 2 diabetes.

The associations of BMI with the MetS risk factors represent the combined result of the LMI, FMI and AbFI. As shown earlier, in men, LMI has no, while FMI has a countering effect on that of AbFI. Thus depending on the strength of these opposing components, the resulting association will be reflected by the high BMI groups. In the present study, it appears that men with high BMI reflect the adverse association of high AbFI on the MetS risk factors, and overwhelming the cardio-protective association of high FMI. In women, on the other hand, the combined negative associations of FMI, LMI and AbFI as represented by BMI appear to have an additive effect on the risk factors. Taken together, the gender differences shown in the present study can, perhaps explain why some studies appear to show an obesity paradox on MetS [14, 26].

\section{Conclusion}

The present study shows that LMI, FMI, and AbFI have independent relationship and BMI reflect the resultant relationship of these three indices with the various MetS risk factors. In addition, apart from AbFI, the independent relationships between LMI, FMI and BMI and the MetS risk factors are distinctly different between men and women. Besides the degree and location of adiposity, and amount of lean mass, other known predicators of the MetS include age, diet, and engagement in physical activities, and in women whether they are premenopausal, postmenopausal and whether they are on and what type of hormone replacement therapy (HRT) [18, 19]. In men, higher testosterone levels are cardio-protective being associated with lower TG, TG/HDL and TC/HDL and higher HDL levels than men with lower levels of testosterone [Goh, unpublished data]. The new findings from the present study provide additional prognostic information to assess the individual risk for MetS and hopefully help in designing effective management plans specific for men and women.

\section{Declaration of Interest}

The author does not have any possible conflicts of interest.

\section{Acknowledgements}

I would like to acknowledge the technical assistance from staff of the Endocrine Research and Service Laboratory of the Department of Obstetrics and Gynaecology, National University of Singapore, Singapore. This study was designed, conducted and data collected while Prof. Victor Hng Hang Goh was at the Department of Obstetrics and Gynaecology,
National University of Singapore, Singapore. This study was supported, in part, by funds from the Academic Research Fund of the National University of Singapore, Singapore.

\section{References}

[1] Mottillo S, Filion KB, Genest J, et al. The metabolic syndrome and cardiovascular risk: a systematic review and meta-analysis. J Am Coll Cardiol 2010; 56 (14): 1113-32.

[2] Stocks T, Bjorge T, Ulmer H, et al. Metabolic risk score and cancer risk: pooled analysis of seven cohorts. Int J Epidemiol 2015; 44 (4): 1353-63.

[3] Ford ES. Risks for all-cause mortality, cardiovascular disease, and diabetes associated with metabolic syndrome: a summary of the evidence. Diabetes Care 2005; 28 (7): 1769-78.

[4] Ranasinghe P, Mathangasinghe Y, Jayawardena R, Hills AP, Misra A. Prevalence and trends of metabolic syndrome among adults in the Asia-pacific region: a systematic review. BMC Public Health 2017; 17 (1): 101 doi.org/10.1186/s12889-0174041-1.

[5] Moore JX, Chaudhary N, Akinyemiju T. Metabolic Syndrome Prevalence by Race/Ethnicity and Sex in the United States, National Health and Nutrition Examination Survey, 19882012. Prev Chronic Dis 2017; 14: E24. doi: $10.5888 /$ pcd14.160287.

[6] Expert Panel on Detection, Evaluation, and Treatment of High Blood Cholesterol in Adults. Executive summary of the third report of The National Cholesterol Education Program (NCEP) (Adult Treatment Panel III). JAMA 2001; 285 (19): 2486-97.

[7] Goh VHH. Effects of menopause, hormone replacement therapy and aging on the health in Asia women. Arch Women Health Care 2019; 2 (1): 1-11.

[8] Liao C-C, Sheu WH-H, Lin S-Y, Lee W-J, Lee I-T. The relationship between abdominal body composition and metabolic syndrome after a weight reduction program in adult men with obesity. Diabetes Metab Syndr Obes 2020; 13: 1-8. doi: 10.2147/DMSO.S228954.

[9] World Health Organization. Obesity: preventing and managing the global epidemic. Report of a WHO consultation. World Health Organ. Tech. Rep. Ser. 2000; 894: 1-253.

[10] Goh VHH, Tain CF, Tong TYY, Mok PP, Wong MT, Are $\mathrm{BMI}$ and other anthropometric measures appropriate as indices for obesity? A study in an Asian population. J. Lipid. Res. 45 (2004) 1892-8.

[11] Romero-Corral A, Somers VK, Sierra-Johnson J, et al. Accuracy of body mass index in diagnosing obesity in the adult general population. Int J Obes. Lond. 2008; 32: 959-966. doi: $10.1038 /$ ijo.2008.11.

[12] Bonikowske AR, Lara MIB, Koepp KE, et al. Fat mass index better identifies metabolic syndrome: Insights from patients in early outpatient cardiac rehabilitation. J Clin Med 2019; 8 (12): 2147. doi: $10.3390 / j \operatorname{cn} 8122147$.

[13] Goh VHH, Tong TYY, Mok PP, Said B, Interactions among age, adiposity, bodyweight, lifestyle factors and sex steroid hormones in healthy Singaporean Chinese men. Asian J. Androl. 9 (2007) 611-21. 
[14] Goh VHH, Hart WG. Association of physical exercise as a lifestyle habit with lean and fat body mass and handgrip strength and age in Asian men. Aging Male 17 (2014) 131-5.

[15] Kelly TL, Wilson KE, Heymsfield SB. Dual energy X-Ray absorptiometry body composition reference values from NHANES. PLoS ONE 2009; 4: e7038. doi: 10.1371/journal.pone.0007038.

[16] McLaughlin T, Abbasi F, Cheal K, Chu J, Lamendola C, Reaven G. Use of metabolic markers to identify overweight individuals who are insulin resistant. Ann Intern Med 2003; 139: 802-9.

[17] Matthews DR, Hosker JP, Rudenski AS, Naylor BA, Treacher DF, Turner RC. Homeostasis model assessment: insulin resistance and beta cell function from fasting plasma glucose and insulin concentrations in man. Diabetologia 1985; 28: 412-9.

[18] Goh VHH. Health benefits of physical exercise as a lifestyle habit in Asian men and women. Int Arch Public Health Community Med 2018; 2: 011.

[19] Karastergiou K, Smith SR, Greenberg AS, Fried SK. Sex differences in human adipose tissues - the biology of pear shape. Biol Sex Differ 2012; 3: 13 doi: 10.1186/2042-6410-313.

[20] Savage PD, Banzer JA, Balady GJ, Ades PA. Prevalence of metabolic syndrome in cardiac rehabilitation/secondary prevention programs. Am Heart J. 2005; 149: 627-31.

[21] Medina-Inojosa JR, Somers VK, Thomas RJ, et al. Association between adiposity and lean mass with long-term cardiovascular events in patients with coronary artery disease: No paradox. J Am Heart Assoc. 2018; 7: e007505. doi: 10.1016/JAHA.117.007505

[22] Haberka M, Stolarz-Skrzpek K, Biedron M, et al. Obesity, visceral fat, and hypertension-related complications. Metab Syndr Relat Disord 2018; 16 (10): 521-9.
[23] Wronska A, Kmiec Z. Structural and biochemical characteristics of various white adipose tissue depots. Acta Physiologica 2012; 205 (2): 194-208.

[24] Goodpaster BH, Thaste FL, Kelley DE. Thigh adipose tissue distribution is associated with insulin resistance in obesity and in type 2 diabetes mellitus. Am J Clin Nutr 2000; 71 (4): 88592.

[25] Leskinen T, Sipila S, Kaprio J, Kainulainen H, Alen M, Kujala UM. Physically active vs. inactive lifestyle, muscle properties, and glucose homeostasis in middle-aged and older twins. Age, 2013; 35 (5): 1917-26.

[26] Goodpaster BH, Krishnaswami S, Resnick H, et al. Association between regional adipose tissue distribution and both type 2 diabetes and impaired glucose tolerance in elderly men and women. Diabetes Care. 2003; 26 (2): 372-9.

[27] Yim J-E, Heshka S, Albu JB, Heymsfield S, Gallagher D. Femoral-gluteal subcutaneous and intermuscular adipose tissues have independent and opposing relationships with CVD risk. J Appl Physiol 2008; 104 (3): 700-7.

[28] Goh VHH, Hart WG. Excess fat in the abdomen but not general obesity is associated with poorer metabolic and cardiovascular health in premenopausal and postmenopausal Asian women. Maturitas 2018; 107: 33-8.

[29] Campos RMDS, Masquio DCL, Corgosinho FC, Caranti DA, Ganen AP, Tock L, Oyama LM, Dâmaso AR. Effects of magnitude of visceral adipose tissue reduction: Impact on insulin resistance, hyperleptinemia and cardiometabolic risk in adolescents with obesity after long-term weight-loss therapy. Diab Vasc Dis Res 2019; 16 (2): 196-206. doi: $10.1177 / 1479164118825343$. 